\title{
Achieving Agility of Supply Chain Management through Information Technology Applications
}

\author{
Yi Wu and Jannis Angelis \\ Warwick Business School, University of Warwick, Coventry, CV4 7AL, \\ UK \\ Yi.Wu05@wbs.ac.uk: \\ Jannis.Angelis@wbs.ac.uk
}

\begin{abstract}
Agility in supply chains is critical for competitive advantages as it helps to explore and exploit opportunities in fast changing markets. Firms are increasingly dependent on information technology (IT) for supply chain management as a competitive tool to facilitate such agility. However, little research has been done on the role of IT on supply chain agility. The paper aims to address this gap by further investigating how IT applications affect supply chain agility. We propose that IT infrastructure integration, consisting of data consistency and cross-functional application integration is critical to achieve agility as various integration processes in agile supply chains can be hampered by fragmented IT infrastructures which enable information flow and coordination activities across function units and network partners. We further illustrate IT infrastructure integration impacts on agility in various operational dimensions, such as speed, flexibility across the supply chain.
\end{abstract}

Keywords

Information technology infrastructure, Supply chain agility, Flexibility,

Responsiveness

\section{Introduction}

Agility in the supply chain is critical for competitive advantages as it helps to explore and exploit opportunities under time-to-market pressures, and seeks to provide prompt response to customer requirements at an acceptable cost. It has 
gained the significant attentions from both academics and practitioners currently [13 ] and it has been a main objective for leading companies [4].

Firms are increasingly dependent on information technology (IT) for supply chain management as it can help to reduce cost, shorten product life cycle and increase information visibility across supply chains [5]. IT is also recognized as an important role in supply chain agility, as Breu et al [6] ague that 'information systems are seen to assume a fundamental role in developing agility'. Particularly, in pursuing of supply chain agility, various integration processes can be hampers by fragmented IT infrastructure which enables information flow and coordination activities across functional units and network partners [7].

Despite the critical role of IT that has been identified in supply chain management $[3,8]$, theoretical and empirical research pertaining to the impacts of IT infrastructure on supply chain agility has been limited. We draw the concepts from related literatures on IT infrastructure, supply chain agility and supply chain operations to develop key constructs and relationships. We focus on the critical factors of IT infrastructure for supply chain agility which consists of various integrations, and the impact of IT on agility. More specifically, we address the following questions: 1) What are the values of applying IT in supply chain agility? 2) How does IT infrastructure impact supply chain agility?

The paper is organized as follows. Section 2 presents a review of literature on supply chain agility and the relationship of IT with agile capabilities of supply chain management, while section 3 proposes our framework and relevant propositions. The paper closes with theoretical and managerial implications.

\section{Literature Review}

Supply chain management (SCM) is moving from vertical integration to horizontal integration, involving inter-firm integration and extensive outsourcing to achieve efficiency [9]. Within the time-based competition, agility is becoming important as it is about 'customer responsiveness and mastering market turbulence' [9]. Goldman et al. [10] identified four basic dimensions of agility: enriching customers, cooperating to enhance competitive advantages, organizing to master change and uncertainty and leveraging the impact of people and information. The definition provides a basic conceptual view with the relevant elements of agility, stressing the responses to changes and capturing changes as opportunities [11].

In the context of supply chain, agility lies in the same theoretical premises as agile manufacturing [12]. More specifically, Aitken et al. [13] propose a three-level model with key principles to agile enterprises from rapid replenishment, lean production and organizational agility to individual action. In the research of van Hoek et al.[9], four dimensions of agile supply chain have been identified, which are customer sensitivity for a customer oriented supply chain; virtual integration to leverage information across supply chains; process integration to master changes through focusing on core competencies and network integration to coordinate with partners[ 1,9$]$. Many studies have shown that the integration of supply chains at a 
multi-enterprise level can create competitive advantages and improve the overall performance $[17,18]$.

In the case of automotive industry, the supply chain is characterized by complexity, uncertainty and heterogeneity [15]. A large number of studies illustrate the strategic importance of agile manufacturing $[11,16]$. Specifically, in the automotive industry supply chain which is heavily dependent on the whole supply chain, a single agile manufacturing enterprise may have difficulties responding rapidly to changing market requirements due to limited resources [15].Employing an IT system that links customers and suppliers at various stages through real time communication and information exchange may enable innovative and cost-effective product design [17].

IT plays a key role on the various integration processes as synchronizing suppliers in the network by providing real time information [17]. Therefore, through the agile capability to realize operation on actual demand, information should be instantly available through information sharing and exchange and organizations are designed for maximum efficiency during integration processes [14]. A bulk of literature has addressed the benefits of IT on SCM from direct operational benefits to the creation of strategic advantages [19,20]. Levary [19] illustrates several implications such as product cycle time. Meanwhile, suppliers may provide better collaboration with an OEM due to the IT applications [10]. In particular, when agility is needed, IT is of particular importance [21].

However, the integration processes in supply chains can be hampered by the fragmented IT infrastructure, which enables information flows and coordination activities across functional units and network partners. A well-integrated IT platform is not only the individual physical parts as it requires the standards for integration of data, applications, and processes to realize the information flow $[22,23]$. The two construct important to IT infrastructure are data consistency which should enable the process integration [20] including the information flow by defining key entities to realize information sharing, and cross-functional application integration which enables the management of the supply chain-related processes and realizes the ability to interface with supply chain applications among partners in real time [23].

\section{Research Model and Propositions}

In agile supply chain, customer sensitivity emphasizes customers and markets, including customer-focused logistics and rapid response. Supply chains are becoming demand-driven rather than forecast-driven in order to effectively respond in real-time demand. With IT infrastructure integration, supply chain partners can capture data on demand, thus leading to customer-focused supply chains [1]. Thus we propose that,

P1a IT has a positive impact on responding to changes in production and services

P1b IT has a positive impact on the responsiveness of processing market demands on new products

It is critical to leverage the strengths and competencies of partners to realize fast responsiveness to market requirements [1], which is called network competition. This can be interpreted as a company's dependability on its partners. This research 
regards dependability as coordinating with partners while focusing on their own competencies through network integration. Thus we propose that,

P2 IT increases the degree of dependability among partners in the supply chain

Process integration is related to uncertainty across the supply chain, placing emphasis on self-management teams so that core modules of products can be delegated. Alliances among various suppliers, manufacturers and customers will be inevitable [24].Therefore, while focusing on their own competencies, companies are much more likely to increase product variety and improve the ability to handle orders with special requirements. Thus we propose that

P3 IT improves product and volume flexibility along the supply chain

Virtual integration emphasizes on leveraging people and information along the supply chain. Information gathering and dissemination [26] are two important attributes towards organizational learning, a key dimension for SCM, given the complex and often dynamic nature of SCM [27]. Due to IT enhanced connectivity, individuals can share their own interpretations of information to make consensusfocused development more efficient. Thus we propose that,

P4 IT positively impacts on information acquisition and dissemination of organizational learning.

The model in Figure 1 indicates the operations impact of IT on agile capabilities of the supply chain.

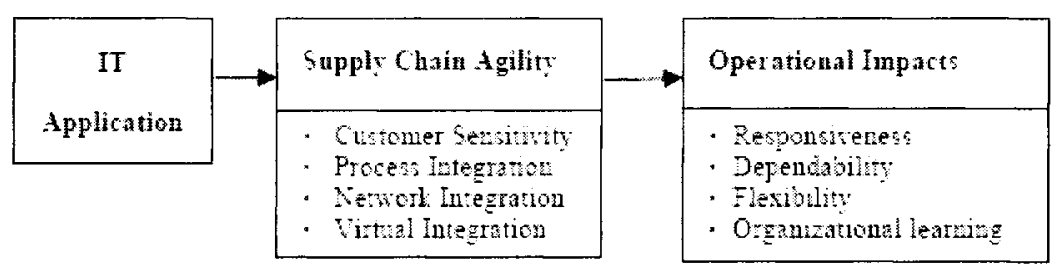

Fig. 1.Conceptual Framework

\section{Case Study}

We conducted multiple case studies in Chinese automotive companies, where firms pursue effective operations to meet rapid growth and demanding customers in which supply chain performance plays a crucial role on sustaining competitive advantage. Semi-structured interviews were deployed in order to gain an in-depth understanding of the broader organizational patterns of information technology applications and their relation to supply chain agility, and a survey used to test propositions. 


\subsection{Case Background}

The studied companies are operating in a volatile and competitive market as customers are increasingly demanding with changing needs which is relevant to Goldman et al [10] description of agility.

The OEM (A) is one of the biggest auto manufacturers in China with its own $R \& D$. The company is facing the multi-market competition from Japanese, Korean, American and European auto makers. However, the company seeks for the emerging market and can lunch new models with good quality and low cost in short time based on market demands. It has a close relationship with its suppliers on the product design and development.

The $1^{\text {st }}$ tier supplier (B) is a manufacturer of automotive seating systems for various auto makers. According to the $\mathrm{CEO}$, the automotive industry is driven by cost and there are increasing pressures and constant changes in customer requirements. At present, the company hopes that the OEM can provide the technology to realize real time communication and information exchange in order to improve the overall supply chain performance.

The $2^{\text {nd }}$ tier supplier (C) is manufacturing the foams for the automotive seating system and has the competitive advantage on the production processes in China, although it is a relatively new entrant ( $2 \mathrm{yrs})$. They have a close link with its customers across this chain, as it has already involved in the new vehicle model $\mathrm{R} \& \mathrm{D}$ process in OEM. On the other hand, it has already realized the inventory share with some customers through IS integration to establish a close relationship with customers at the strategic level, according to the CEO.

\subsection{IT Applications in the Companies}

Table 2 provides details of the IT employed in each company. In Company A, they develop ERP cooperated with third party. IT is based on the standard ERP solution with the features presenting their own business characteristics. The data are consistent across departments to ensure information flow. Accordingly, Company B is using a standard ERP system. However, due to the lack of management skills and relevant knowledge, finance department needs to entry all data manually. Therefore, it increases the data inaccuracy in the business process. As for Company $\mathrm{C}$, due to the business increasing in terms of customers, they find that MRP can not fully support the business.

There is only one way connection from Company A to B through the platform A established for supplier management to delivery monthly, weekly and daily planning so that Company $\mathrm{B}$ can produce their manufacturing schedule and procurement planning. Company $\mathrm{A}$ is considering of building up a real time information exchange system and share with suppliers, but the problem is whether suppliers would like to share their information.

Only email communication set up among Company B and C, which constrains overall performance. The CEO of Company B acknowledged the company's need for a closer electronic interaction with the suppliers to increase overall competitiveness. 
Table 1. IT applied in the company

\begin{tabular}{llll}
\hline Company & Application & Description & Type \\
\hline OEM -A & MySAP & ERP Solution & Commercial off the shelf \\
$1^{\text {st }}$ Supplier-B & UF & ERP Solution & Commercial off the shelf \\
$2^{\text {nd }}$ Supplier $-C$ & No Name & MRP Solution & In house software development \\
\hline
\end{tabular}

\subsection{Operational Impact of IT}

The interviewees from the above three companies concluded that the impacts of IT applications are significant on the operational dimensions. As one senior manager from logistics department described, "without IT, all the operation processes will be in a mess'.

\section{- Responsiveness}

In Company $\mathrm{A}$ and $\mathrm{C}$ all departments share information so as to make the fluent information flow so as to improve the responsiveness of the change and the process from downstream/upstream. Considering the lack of knowledge on IT applications, the company found that without integrated IS, it threats data accuracy which affects the responsiveness of the business processes. The CEO of Company $\mathrm{B}$ agreed that through the portal of SRM they have coordinated planning mechanisms and process alignment across the corporate boundaries due to the IT connectivity. However, the demand information is restricted to suppliers; suppliers can not get any information directly from end-customers to schedule their manufacturing. Therefore, because information on end-customer requested change is delayed from the OEM to the suppliers, the latter have limited time to re-schedule their daily manufacturing. The findings indicate that companies are moving towards a more integrated supply chain in order to have the competitive advantages of the overall supply chains, but so far at a slow rate.

- Dependability

Under the dynamic and changing markets, it is difficult for companies be responsive. Coordination is becoming critical. As in this case, suppliers are increasingly involved on collaborative working product design, and can focus more on their competencies.

However, results from the survey show that IT does not have a great impact on a single supplier on each sourced product as most interviewees pointed out that IT facilitates the connection between partners through the information share process, such as planning and inventory. For example, suppliers are planning their manufacturing schedules based on OEM plans. With instant access to the OEM's manufacturing execution schedule (which is updated every two hours) it is easier for the suppliers to operate an outbound JIT system and have lower inventory levels than before the IT integration. Being in an industry driven by cost, company A engages into several collaborations with various suppliers for each product sourced.

\section{- Flexibility}

The findings suggest that IT has a great impact on the realization of product and volume flexibility, because of the visibility IT provides. As the CEO from Company $B$ remarked, the flexibility of volume, products and delivery time is really important. However, the company needs to have the ability to handle non-standard orders at the shop floor. Therefore, the company is working on improving operations flexibility. 
- Organizational learning

Given high information availability among partners, it is imperative to achieve technology integration throughout the supply chain by adopting EAI or EDI systems to provide employees with high information availability.

\section{Discussion and Conclusions}

The exponential increase of corporate investment on IT suggests a strong impact of IT applications on reshaping and improving firm capabilities. However, it has been recently argued that IT cannot create value in a vacuum, as illustrated by the significant failure of IT firms to create sustained growth in high technology markets [29]. In this paper, we investigate indirect links of IT and corporate value creation. In doing so, we focus on supply chains, and more specifically on supply chain agility. Our research is motivated by the importance of IT on supply chain agility in complex manufacturing environments such as the automotive industry. We develop a conceptual model to address the theoretical gap of IT, supply chain agility and value creation.

This paper has several theoretical and practical implications. First, we extend the current literature of IT and supply chain agility by investigating the impact of IT and the possible ways of realizing value. Moreover, we highlight the role of IT as a platform for various integration processes in an agile supply chain and the direct link among IT application, agility and operational drivers.

Second, we lay the theoretical ground for applying IT to achieve supply chain agility. This paper illustrates how IT applications affect specific operational drivers on achieving agility. Furthermore, we provide an integrated perspective of IT and supply chain agility and illustrate how to leverage IT applications along agile supply chains to improve its responsiveness, dependability and flexibility.

In terms of management practice, we found that the succesfull application of IT systems across the supply chain it is not dependent on the technology adopted throughout per se, but rather the continuous engagement of trading partners. As one senior manager points out "sometimes it is not technology problems, but that the suppliers do not want to share their inventory". Furthermore, our case study findings suggest that the information flow across the supply chain was limited. We suggest that low information transfer among partners may impede several operational capabilities, such as flexibility. Last, we found a misalignment between existing IT management practices and applications being implemented. Put it differently, we suggest that managers should steer considerable effort towards efficient data integration and analysis in order to gain from the implementation of complex IT systems. Under this stream, we raise managerial attention to further training of efficient IT management.

\section{References}

1. M. Christopher, The Agile Supply Chain-Competing in Volatile Markets, Industrial Marketing Management, 29 (1), 37-44(2000). 
2. J.B.Naylor, M.M. Naim, and D.Berry, Leagility: Integrating the Lean and Agile Manufacturing Paradigms in the Total Supply Chain, International Journal of Production Economics, 62 (1/2), 107-118 (1999).

3. D. J. Power, A.S. Sohal, and S. Rahman, Critical Success Factors in Agile Supply Chain Management, International Journal of Physical Distribution \& Logistics Management, 31(4), 247-265 (2001).

4. M. L. Fisher, What is the Right Supply Chain for Your Product? Harvard Business Review, 75(2), 105-116 (1997).

5. R. R. Levary, Better Supply Chains through Information Technology, Industrial Management, 42(3), 24-30(2000).

6. K. Breu, C. Hemingway, M. Strathern, \& D.Bridger, Workforce Agility: The New Employee Strategy for the Knowledge Economy, Journal of Information Technology, 171, 21-31(2001).

7. A. Barua, P. Konana, A.B. Whinston, and F.Yin, Assessing Net-Enabled Business Value: An Exploratory Analysis, MIS Quarterly, 28(4), 585-620 (1995).

8. A. Gunasekaran,and E.W.T. Ngai, Information Systems in Supply Chain Integration and Management, European Journal of Operational Research, 159, 269-295 (2004).

9. R. I.Van Hock, A. Harrison, and M. Christopher, Measuring Agile Capabilities in the Supply Chain, International Journal of Operations \& Production Management, 21(1/2), 126-147(2001).

10. S.L. Goldman,R.N.Nagel, and K. Preiss, Agile Competitors and Virtual Organisations (Van Nostrand Reinhold, New York, 1995).

11. H.Sharifi, and Z. Zhang, a Methodology for Achieving Agility in Manufacturing Organization: An Introduction, International Journal of Production Economies, 62,722(1999).

12. H.S. Ismail, and H. Sharifi, (2006), A Balanced Approach to Building Agile Supply Chains, International Journal of Physical Distribution \&Logistics Management, 136 (6), 431-444 (2006).

13. J.Aitken, M. Christopher, and D. Towill, Understanding, Implementing and Exploiting Agility and Leanness, International Journal of Logistics: Research and Applications, 5 (1), 59-74(2002).

14. Y.Y.Yusuf, A.Gunasekaran, E.O.Adeleye, and K. Sivayoganathan, Agile supply Chain Capabilities: Determinants of Competitive Objectives, European Journal of Operational Research, 159, 379-392(2004).

15. H.Q.Xu, C.B.Besant, and M.Ristic, System for Enhancing Supply Chain Agility through Exception Handling, International Journal of Production Research, 41(6), 1099$1114(2003)$.

16. K.Cheng, D.K.Harrison, and P.Y. Pan, Implementing of Agile Manufacturing-An AI and Internet Based Approach, Journal of Materials Processing Technology,76, 96-101(1998)

17. M. Christopher, Logistics and Supply Chain Management: Creating Value-adding Networks (Prentice Hall, London,2005).

18. R.E.Spekman, and K.JW.N. Myhr, An Empirical Investigation into Supply Chain Management: A Perspective on Partnership, Supply Chain Management, 3(2), 53-67(1998).

19. R.R.Levary, Better Supply Chains through Information Technology, Industrial Management, 42 (3), 24-30(2000).

20. T.W.Malone, J.Yates, and R.L. Benjamin, Electronic Markets and Electronic Hierarchies, Communications of the ACM,30 (6), 484-497(1987). 
21. S. Vickery, C. Droge, and R. Markland, Dimensions of Manufacturing Strength in the Furniture Industry, Journal of Operations Management, 15,317-330(1997).

22. J.W.Ross, Creating a Strategic IT Architecture Competency: Learning in Stages, MIS Quarterly Executives, 2(1), 31-43 (2003).

23. A. Rai, R. Patnayakuni, and N.Seth, Firm Performance Impacts of Digitally Enabled Supply Chain Integration Capabilities, MIS Quarterly, 30(2), 225-246(2006).

24. H. Lee and C. Billington, Managing Supply Chain Inventory: Pitfalls and Opportunities, Sloan Management Review, 33 (3), 65-7(1992)

25. M.Christopher, and D.R.Towill, Supply Chain Migration from Lean and Functional to Agile and Customized, Supply Chain Management: An International Journal, 5 (4), 206213(2000).

27. M.J.Tippins, and R.S. Sohi, IT Competency and Firm Performance: Is Organizational Learning a Missing Link?, Strategic Management Journal, 24, 745-761(2003).

28. G.T.M.Hult, R.F.Hurley, L.C. Giunipero, and Jr. E.L. Nichols, Organizational Learning in Global Supply Management: a Model and Tests of Internal Users and Corporate Buyers, Decision Sciences, 31 (2), 293-325(2000).

29. T.C.Powell, and A. Dent-Micallef, Information Technology as Competitive Advantage: the Role of Human, Business and Technology Resources, Strategic Management Journal, 18(5), 375-405 (1997). 